\title{
trabalhonecessário
}

issn: $1808-799 \mathrm{X}$

ano 3 número $3-2005$

\section{Educación y Trabajo: un debate fundamental para reconquistar el valor de lo social.}

Roberto Gerardo Bianchetti

CIUNSa. Universidad Nacional de Salta - Argentina

\section{INTRODUCCION}

La necesidad de los seres humanos de proveerse de algunos de los bienes de la naturaleza para su subsistencia, convierte al trabajo, como concepto ontológico, en una de las condiciones ineludibles y necesarias para la existencia de una sociedad.

Algunos autores sostienen que las sociedades logran su permanencia través del tiempo, a partir de la utilización de tres mecanismos de reproducción : biológica, económica y social o cultural.[1]

La reproducción biológica, es la que asegura la continuidad de la existencia humana y genera, a partir del modelo familiar que produce, relaciones sociales cuyas características son la manifestación de un tiempo y espacio determinado.

La reproducción económica pone en acción los mecanismos utilizados en la sociedad para la producción y distribución de los bienes, situación que implica una relación de los seres humanos con la naturaleza, a través de los instrumentos creados para esos fines, como también las interacciones que se generan entre sus miembros. 
En este caso, si en el análisis de una sociedad concreta, también se introducen las dimensiones de tiempo y espacio, es posible encontrar algunas respuestas sobre sus características particulares. (grado y tipo de desarrollo, criterios de redistribución, etc.)

El tercer mecanismo utilizado en las sociedades para garantizar su permanencia incluye diferentes estrategias de socialización que tienen como objetivo principal, integrar al colectivo social.

Todas las instituciones sociales que se constituyen durante el desarrollo de estos procesos de reproducción social, están involucradas en la producción y difusión de valores, principios, creencias, que se convierten en los saberes colectivos que otorgan sentidos a las prácticas sociales y conforman la cultura de esa sociedad.

El acceso a esos conocimientos no se produce de forma igualitaria ni homogénea para los diferentes grupos o sectores sociales y aquellos que poseen el control sobre los mecanismos desde los cuales se ejerce el poder (político, económico o ideológico), las acciones más importantes son las que favorecen la integración y cohesión de los miembros que forman parte del colectivo. Esto último requiere tanto de la construcción de una identidad en la que se sientan involucrados, como la aceptación y reconocimiento de la legitimidad de un determinado orden social.

Con lo expuesto hasta aquí, es posible reconocer que en el trasfondo de todas estas prácticas, el elemento común es la acción del hombre para producir su propia existencia, lo que supone identificar que el trabajo humano, en un sentido amplio, se convirtió en el elemento central de las sociedades a través del tiempo, aunque su consideración como principio o su reconocimiento como valor, haya variado sustantivamente a lo largo de la historia.

La importancia que adquiere hoy su estudio tiene relación directa con la magnitud y la incidencia de los cambios operados en las sociedades en los últimos cincuenta años, los que por sus características implicaron, en ciertas dimensiones, una ruptura con toda una dinámica pre-existente.

En este contexto la relación entre educación y trabajo coloca nuevos elementos que intentaremos hacerlos evidentes con el objetivo de colaborar en el debate.

\section{EL TRABAJO EN LOS ORIGENES DE LA MODERNIDAD}

La centralidad que adquiere el tema del trabajo en las sociedades capitalistas, es el resultado del sentido y valor que el mismo va adquiriendo para la producción industrial. Sin embargo la atención sobre ese aspecto de la formación humana, es una de las preocupaciones puesta de manifiesto por los movimientos de reforma social y política durante la transición entre el antiguo régimen y la naciente modernidad.

Las primeras expresiones destacadas en relación con este tema, se remontan a algunas reformas introducidas durante los siglos XVI y XVII. Para Gadotti, en esta época se asiste a la "asención de una nueva y poderosa clase que se oponía al modo de producción feudal. Ese estrato de la sociedad impulsó, modificó y concentró nuevos medios de producción. Inició el sistema de cooperación, precursor del trabajo en serie del 
siglo XX". [2 ]

Por otra parte y como consecuencia natural de la transición entre dos sistemas sociales diferentes, Manacorda, destaca el sentido contradictorio que adquiere este tema para Rousseau en el Emilio (Siglo XVIII) ya que si bien el sujeto utilizado como modelo provenía de una familia noble, los "nuevos aires" ya se hacían sentir. Según la percepción de ese pensador "nos acercamos a una situación de crisis y al siglo de las revoluciones... y la naturaleza no hace príncipes ni ricos ni grandes señores. Feliz quien sabe abandonar sus privilegios y convertirse en un hombre prescindiendo de su suerte...Trabajar es un deber indispensable para el hombre social. Rico o pobre, poderoso o débil, todo ciudadano ocioso es un sinvergüenza..." [3]

Con anterioridad Locke le había otorgado al trabajo una función central en la explicación del tránsito entre el "estado de naturaleza" a la sociedad civil. El argumento de que la apropiación de los bienes, en la sociedad de naturaleza, era consecuencia del trabajo humano, constituye uno de los argumentos de mayor peso utilizado para justificar la propiedad privada en las sociedades capitalistas, en la medida que sitúa a ese derecho como un componente de la relación hombre-naturaleza, anterior al contrato social y al derecho positivo. [4]

Esta nueva valoración del trabajo constituye, durante estas etapas históricas, una ruptura radical con las tradiciones medievales donde el trabajo estaba reconocido sólo en el ámbito de las clases subalternas.

A medida que las sociedades se incorporaban a la dinámica impuesta por la industrialización, el campo de las ideas se conmovía con el debate generado por la nueva entidad social que adquiría el trabajo. Las expresiones políticas a través de las cuales se expresaban estas ideas constituían cosmovisiones diferentes y en algunos casos antagónicas, ya que mientras para los que adherían al nuevo modo de producción capitalista, el trabajo representaba un atributo que servía para integrarse a la sociedad y acceder a los bienes en ella producidos, para otros, críticos de ese sistema económicosocial, el trabajo, que era un constituyente natural del proceso de hominización del ser humano, se había transformado, como consecuencia del modo de producción capitalista, en una forma de alienación y sometimiento.

La concepción liberal y la marxista, van a ser las expresiones que ocuparán el centro del debate político sobre este tema, durante los siglos XIX y XX, manteniendo su vigencia hasta la actualidad.

\section{EDUCACION Y TRABAJO EN LAS SOCIEDADES MODERNAS}

El Estado-Nación es la forma como las sociedades modernas organizaron su sistema de dominación y como en todo proceso de cambio social, se requirieron determinadas tareas destinadas a, instaurar, consolidar y estabilizar el nuevo orden social.

Algunos autores reconocen la existencia, en las primeras etapas, de diferentes estrategias impulsadas por los grupos sociales dominantes, con el objetivo de controlar las 
instituciones a través de las cuales se ejerce el poder. Oszlak identifica a esas estrategias como: "represiva", "material", "cooptativa" e "ideológica" y cada una de ella cumple una función importante en el proceso de conformación del Estado, ya que operan como mecanismos destinados a facilitar el control social.[5]

El monopolio en el uso legítimo de la fuerza, es una de las condiciones necesarias para llevar a la acción las propuestas políticas requeridas desde el modelo de desarrollo económico-social, al que adhieren los que detentan el poder. Esta función coincide con la clásica definición de Weber sobre las características y condiciones para la existencia del Estado moderno.[6]

La búsqueda de alianzas, constituye una de las primeras lecciones de la teoría política y esto se logra a través de diferentes mecanismos. La estrategia material es una de ellas, ya que se utiliza para conquistar adhesiones a un determinado proyecto político por medio de la ejecución de acciones concretas (caminos, puentes, servicios públicos, etc.) impulsadas desde un ámbito de poder (central) hacia otros (locales o regionales).

Una condición necesaria, para lograr el fortalecimiento del poder entre quienes convinieron las alianzas, es que estas acciones sean percibidas como necesarias por el colectivo social.

Las estrategias de cooptación crean relaciones y compromisos que facilitan la ejecución de acciones políticas concebidas por los sectores o grupos sociales que se proponen construir una determinada hegemonia.

Todas estas acciones forman parte de las tareas políticas prioritarias en las etapas de construcción de los estados nacionales y para alcanzar la estabilidad del orden social es necesario transformar los intereses parciales (de grupos, clases o sectores sociales) en interés común (social).

Lograr instalar como valor social lo que representa un interés parcial, constituye la materialización del concepto de Hegemonía desarrollado por Gramsci [7] y la "naturalización" de esa forma de organización social se logra a través de la aceptación (por parte de la sociedad) de un discurso (parcial) explicativo sobre la "realidad", como si fuese la expresión materializada de la realidad misma.

En la etapa de surgimiento de los Estados-Nacionales y durante muchos años la educación cumplió un papel fundamental de legitimación, ya que se constituyó en una herramienta de alcance masivo, utilizada por determinados sectores sociales para estabilizarse en el poder o para inculcar determinada concepción del mundo, afín con su filosofía y/o sus intereses.

A esta dimensión de la acción educacional que tiene como principal objetivo generar una identidad que sirva para homogeneizar los comportamientos sociales, se la identifica como la "función política" que cumple la educación y que se concreta cuando se produce la aceptación de principios y valores (parciales) como siendo comunes.

Por otro lado en las sociedades capitalistas en las que se desarrolló este modo de producción de forma originaria, la educación cumplió en esas primeras etapas, otra 
función.

Según Manacorda, "fábrica y escuela nacen a un mismo tiempo: las leyes que crean la escuela de estado van de acuerdo con las que suprimen el aprendizaje corporativo" [8].

La convergencia de intereses entre la fábrica y la escuela pone en evidencia el requerimiento que desde la economía se hizo (desde los orígenes de la educación de masas), hacia las instituciones escolares y si bien la relación entre estas dimensiones de las prácticas sociales, no es mecánica, rígida, ni automática, las "modalidades de formación" introducidas en los sistemas educativos públicos ponían de manifiesto algunos de los intereses ligados al modelo de desarrollo impulsado por los grupos económicos dominantes, que procuraban alcanzar sus objetivos mediante el control, dominio o influencia, sobre el poder político.

\section{DE LA “EDUCACION COMO FORMACION PARA EL TRABAJO” A LA “EDUCACION COMO CAPITAL PARA EL TRABAJO".}

Si bien la demanda de formación técnica relacionada con los requerimientos de la creciente industrialización tuvieron influencia sobre la organización de los sistemas educativos nacionales, los objetivos implícitos en las prácticas educativas no se limitaban a la formación para una actividad requerida desde el mundo del trabajo. Lo más importante era la necesidad de universalizar una formación que naturalizara el orden social existente.

La organización institucional, el aula, el trabajo docente y los contenidos inculcados, todos colaboraban en la tarea de educar al individuo, para que asuma que "debe conducirse a sí mismo" ( Dussell, I. Carusso)[9] , es decir aprender que "hay que gobernarse, controlar los impulsos, comportarse de acuerdo con ciertos códigos y reflexionar sobre las causas y consecuencias de nuestros actos...." [10]. Estos aprendizajes eran coincidentes con las conductas requeridas por las nuevas actividades de la producción o el comercio, como así también con las necesidades del sistema jurídicopolítico. La formación de hábitos en relación a los horarios, el respeto a las jerarquías, el reconocimiento y aceptación de determinados valores, eran algunas de las conductas que, impartidas y legitimadas en la escuela, favorecían el proceso de integración al mundo del trabajo.

La crítica a la alienación que provocaba en el trabajador la organización y dinámica de la empresa capitalista, tuvo su manifestación más sólidamente elaborada en los escritos de Marx y esas ideas constituyeron el punto de partida de una corriente crítica que polemizó y combatió políticamente con las teorías económicas, políticas y sociales que servían de sustento al modelo social capitalista.

Las criticas a los sistemas educativos oficiales, como instrumentos del sistema económico-social, fue la causa de la búsqueda por encontrar formas alternativas de educación. En la primeras épocas (finales del XIX e inicios del XX) los sindicatos identificados como socialistas, anarquistas o comunistas y otras organizaciones populares que representaban los intereses de los trabajadores, se preocuparon por ofrecer una 
educación que sirviera a la emancipación de las conciencias. Si bien en algunos casos esas instituciones jugaron un papel destacado en la alfabetización de los trabajadores, no lograron reemplazar a la creciente expansión de los sistemas públicos y privados de educación.[11]

Las posiciones críticas se orientaron entonces, a tratar de influir sobre las políticas educativas de los gobiernos con el objetivo de modificar la inercia reproductora, atribuida a la educación, aunque también comenzaron a desarrollarse algunas propuestas que conformaron, con posterioridad, las corrientes que promovían el desarrollo de una "Educación Popular", que cumpliera una función liberadora en los pueblos de América Latina.

En el caso de la Argentina, en las primeras décadas del siglo XX, los reclamos de democratización de la educación pública se limitaban a la exigencias por la ampliación de los espacios de integración social y rechazaban cualquier propuesta que fuera percibida como intento por limitar el ascenso a los niveles superiores del sistema. El rechazo a la reforma de Saavedra Lamas (escuela intermedia) en 1916, se realizó con el argumento de que intentaba, con la orientación en formación para el trabajo, seleccionar a quienes podrían continuar dentro del sistema. No es este el lugar para debatir estas opiniones, sólo intentamos mostrar algunas bifurcaciones relacionadas con nuestro tema, ya que en este caso democratización y formación práctica se presentan como polos antagónicos.

La etapa de la historia Argentina donde es posible encontrar una mayor preocupación por relacionar la educación y el trabajo, se produce durante el primer gobierno peronista (mediados del siglo $\mathrm{XX}$ ) aunque, como afirma Pineau citando a Puiggrós "la relación que el peronismo estableció entre sistema escolar y educación laboral es uno de los temas que presenta más dificultades para ser abordado" [12].

Durante el primer y segundo gobierno de Perón (1946-55), se crearon escuelasfábricas, escuelas de aprendizaje, escuelas de capacitación obrera y de capacitación profesional femenina, para concluir con la creación de la Universidad Obrera Nacional.

La formación para el trabajo constituía, en este proyecto político, una de sus principales bases de sustentación, dado que al estar influido por las ideas de los "nacionalismos" europeos, sustentaba la idea de construir un modelo social en el que tuvieran vigencia los principios de "Independencia Económica, Soberanía Política y Justicia Social". El trabajo nacional era concebido como el eje estructurante de las relaciones sociales y garantía de la autonomía frente a los otros Estados.

Este proyecto político fue interrumpido por un golpe militar en 1955 y el derrocamiento implicó también el final de la propuesta educativa.

En esta segunda mitad del siglo XX, en los Estado Unidos comienzan a realizarse estudios que analizaban la relación entre educación y economía, con el objetivo de evaluar la incidencia de la educación sobre el desarrollo económico.

El funcionalismo es una de las corrientes teóricas que logra mayor influencia en el ámbito de los estudios sociales y con relación a la educación, contribuye al estudio, desde 
enfoques diferentes, de la relación entre economía y educación. De esa teoría se perfilan dos orientaciones: la del funcionalismo tecno-económico, que se ocupa de analizar la relación entre educación y desarrollo económico por mediación de la tecnología y la del funcionalismo meritocrático que se centra en el tema de la igualdad de oportunidades de educación y en la incidencia que produce en la mejora de los ingresos, el acceso a los diferentes niveles del sistema educativo[13].

En el marco de estas corrientes, la teoría que logra un mayor desarrollo y en consecuencia mayor influencia ejerce sobre quienes están involucrados con estas problemáticas, es la denominada "Teoría del Capital Humano" que considera que la educación es una inversión que las personas hacen en sí mismas.

Esta teoría utiliza dos dimensiones en el análisis, [14], una macro y otra microeconómica. En la primera se estudia la influencia que ejerce sobre la renta nacional, el aumento de los costes públicos y privados en educación. En la segunda dimensión se analiza cómo un aumento de los años de educación a nivel individual, dará lugar a un aumento de la productividad futura del trabajador y en consecuencia un aumento de sus ingresos.

Estas teorías tuvieron gran influencia en el campo de la Economía de la Educación y se convirtieron en los principios fundamentales utilizados por planificadores y ejecutores de políticas educativas.

El hecho de que en los ciclos de crecimiento económico, la demanda laboral haya mantenido una tendencia de aumento sostenido y como resulta de ello, los egresados de los diferentes niveles del sistema hubieran podido mejorar sus condiciones, favoreció la generalización de estos principios.

En cuanto a la relación entre la educación y el trabajo, se le atribuía a la primera la capacidad de formar los "recursos humanos" requeridos por el sistema productivo y por tal razón la eficiencia del sistema educativo, se medía por el grado de correspondencia entre la respuesta dada por la educación y la demanda del mercado.

En los proyectos políticos que adherían a un modelo de desarrollo económico basado en la industrialización, las modalidades técnicas fueron identificadas como estrategias modernizadoras, en contraposición a las humanísticas que eran consideradas una expresión de la educación tradicional.

Educación para el trabajo era sinónimo de educación para el empleo.

En el campo de las teorías críticas, las respuestas a estos desarrollos teóricos surgió desde las llamadas "teorías de la reproducción social", las que aún proviniendo de matrices teóricas diferentes, se interesan por analizar las funciones de la educación en los procesos de reproducción del sistema social existente.

Toda la elaboración conceptual de estas corrientes se originaba en el estudio de los distintos mecanismos y formas de relación social implicados en el hecho educativo y la manera como cada uno de ellos contribuía a la inculcación de los valores, principios, etc. propios de la cosmovisión de las clases o sectores dominantes de la sociedad. Los 
discursos y las prácticas escolares que cumplían esa función, se hallaban presentes en los contenidos, las relaciones pedagógicas, los modelos institucionales, los regímenes disciplinarios o los sistemas de evaluación.

De este grupo de teorías, las que utilizan categorías de análisis originarias del marxismo, al estudiar la relación entre educación y trabajo, ponen énfasis en la crítica radical a la educación que se imparte en nuestras sociedades, en la medida que sus objetivos son coincidentes con los principios y valores de una economía que mercantiliza todas las relaciones sociales, reproduciendo en el ámbito escolar, la alienación que genera el sistema de producción capitalista (fordismo).

Este desarrollo, fundamentado desde la crítica social, afirma que la fragmentación de los saberes en disciplinas que delimitan campos cerrados de conocimientos, expresaría la ruptura que produce la filosofía liberal en el ámbito de las teorías sociales, dado que al concebir a la sociedad como un agregado aleatorio de átomos independientes que actúan desde principios y lógicas diferente, otorga sentido y valor al conocimiento parcial de la realidad como si fuese la manifestación de la totalidad. Por otra parte, esa separación y fragmentación reproduce las formas como se organiza la línea de producción en las fabricas, en las que el obrero no tiene, en muchos casos, una verdadera noción sobre todo el proceso productivo, no ejerce control sobre el mismo, convirtiéndose en un ejecutor de comportamientos automatizados.

En el área de las ciencias sociales es donde se considera que esta ruptura produce mayor impacto, dado que el contenido de estas disciplinas, cuando no responden a un abordaje basado en el método científico, ocultan los mecanismos de dominación existentes en las sociedades capitalistas.

Una educación fundamentada en una perspectiva histórica, integrada y relacional, ofrecería los saberes necesarios que facilitarían el conocimiento de las formas sutiles de opresión y en consecuencia la comprensión de las causas reales que explican las desigualdades e injusticias de la sociedad capitalista.

"Educación para el trabajo" es interpretada con un sentido "omnicomprensivo" es decir, una formación que, respondiendo a una perspectiva integral y relacional de los hechos y fenómenos sociales, permitiría a los sujetos sociales operar de forma activa, consciente y crítica, superando la pasividad y el conformismo al que son arrastrados por las concepciones legitimadoras del "orden social" existente.

La propuesta pedagógica, que surge desde esta vertiente teórica, colocará el trabajo como "principio educativo", reclamando programas de formación que otorguen valor a la integración entre: trabajo manual/trabajo intelectual; teoría/práctica; conocimiento científico / práctica científica ; pensamiento político crítico / praxis. El concepto de "polivalencia" sintetiza estas ideas.

En relación con las posibilidades de instauración de estos valores, se considera que los verdaderos cambios en la educación no podrán concretarse sin un cambio en la sociedad, aunque se reconoce que es posible avanzar en esa dirección si se logra 
introducir la idea de la necesidad de una formación, que "no perseguirá el mero aprendizaje de una cierta diversidad de técnicas profesionales, sino sobre todo (procurará) que el individuo llegue a la comprensión intelectual y científica del proceso global de producción”.[15]

En América Latina, los mayores desarrollos, dentro de esta perspectiva teórica se encuentra en Brasil, donde existe un grupo importante de investigadores. [16]

\section{EL ESCENARIO DE FIN DE SIGLO}

En las últimas décadas del Siglo XX, una mayoría de países occidentales (del centro y la periferia del sistema) atravesaron por una serie de procesos económicos, políticos y sociales, que transformaron muchas de las instituciones sociales desarrolladas a lo largo del siglo.

Estas instituciones, surgidas como respuestas a dos grandes acontecimientos: la crisis económica del '29 y la segunda guerra mundial, fueron las que dieron contenido a los llamados "Estados de Bienestar", modelos sociales que, con particularidades diferentes, se desarrollaron en la mayoría de los países europeos y en algunos de América Latina.

La particularidad de estos modelos sociales estaba dada, en términos conceptuales, por el abandono, en primer lugar, de algunos de los principios fundamentales formulados por las teorías económicas clásicas, principalmente el referido al carácter autoregulador y espontáneo del mercado y en su reemplazo se reconocía la importancia de introducir algunos mecanismos reguladores, direccionados desde el Estado (keynesianismo), destinados a evitar o moderar las crisis cíclicas de la economía capitalista. En segundo lugar, se desarrollaron formas institucionales para garantizar un cierto nivel de protección social a los ciudadanos, con un criterio solidario y universalista. Los Derechos Sociales, que expresaban los compromisos de protección, representaron una nueva categoría de derechos que dependían, para su concreción, de la acción del Estado a través de políticas públicas activas. El trabajo representaba la condición de existencia y vigencia de esos derechos.

Durante el período definido como "los 30 gloriosos" (mediados de siglo hasta la década del '70) estos modelos sociales desarrollaron en plenitud sus políticas, situación que comenzó a deteriorarse a mediados de esa última década.

La respuesta a los problemas de las economías capitalista en las décadas finales del siglo, provino de los centros de producción teórica del Liberalismo clásico (Escuela de Viena, Universidad de Chicago, Sociedad Mont Pelerin, entre otras).

A estas corrientes se las identificó como "neoliberalismo" y su particularidad como corriente de pensamiento estaba dada por un retorno, en el campo de la economía, a la ortodoxia liberal, mientras en el ámbito de la teoría social y política, se incorporaban principios y valores sustentados por las vertientes conservadoras. 
Los análisis elaborados desde esta matriz teórica, consideraban que las causas de las crisis en las sociedades era consecuencia del abandono de las políticas económicas liberales, reemplazadas por propuestas heterodoxas que habían interrumpido la dinámica del desarrollo de las sociedades. En razón de ello se hacía necesario dejar atrás el "camino de la servidumbre" (Hayek) para retomar la senda de la "evolución natural de las sociedades" lo que implicaba modificar la realidad existente (regulación económica, políticas activas de redistribución) y reinstalar el funcionamiento de la economía de mercado. Si bien la economía ocupaba el papel central en la propuesta de cambio, las estrategias avanzaban en la búsqueda por desmantelar toda la estructura institucional y legal de los modelos de estado benefactor.

Otras de las causas de la crisis en estas sociedades, era atribuida al desarrollo de nuevas tecnologías aplicadas al conocimiento (informática, sistema de comunicaciones ); nuevos conocimientos científicos utilizados para la producción (manipulación genética, robótica, etc.); circulación libre y en tiempo real de los capitales financieros, mundialización de los circuitos de producción y comercio, deterioro de los sistemas de representación política, entre otras.

Esa nueva filosofía se difundió no solo a través de las políticas ejecutadas en algunos países centrales (Gran Bretaña y EEUU), sino que se impuso en algunos organismos multilaterales (BM,FMI), que se convirtieron en ejecutores y supervisores de la aplicación de las nuevas orientaciones políticas. De esa manera los "modelos de ajuste" se transformaron en recetarios instrumentados mecánicamente desde esos organismos.

La educación, que en anteriores períodos históricos era principalmente una preocupación de los estados nacionales, se mundializó a partir del interés demostrado por los organismos multilaterales nombrados anteriormente. Las "reformas educativas", formaron parte de una propuesta global de cambios que incluía: reformas económicas, reformas del Estado y reformas en el sistema político.

El nuevo "modelo social" debía erigirse sobre las cenizas del pasado.

\section{DE LA “EDUCACION COMO CAPITAL” A LA “EDUCACION PARA EL CAPITAL”.}

Tal como expusimos precedentemente, las ultimas décadas del siglo pueden ser consideradas como una etapa en la que se produjo el predominio del ideario neoliberal, que alcanzó cierta hegemonía al constituirse en fundamento de políticas económicas y sociales en la mayoría de los países desarrollados.

En estas sociedades, se realizaron reformas económicas y sociales que debilitaron, en alguna medida, los alcances de los "modelos de bienestar" aunque no lograron desmantelar toda la organización legal e institucional desarrollada a lo largo del siglo XX. Los "Estados de Bienestar" con algunas limitaciones, continuaron existiendo.

Estos programas de reformas se proponían como objetivo final :

1․- Retiro del Estado de la función reguladora en la economía e introducción o fortalecimiento de los mecanismos de mercado para la redistribución de bienes y recursos. 
2ํ.- Retiro del Estado de las instituciones de protección social y fomento a la privatización de esas acciones.

3․- Privatización de las empresas estatales de servicios.

4ํ․- Descentralización de la organización administrativa.

5․- Apertura de las economías al comercio internacional y a la inversión especulativa.

\section{6.- Protección a las inversiones de capital.}

Todas estas estrategias, instrumentadas con matices diferentes de acuerdo a las condiciones existentes en cada sociedad, pusieron en evidencia un cierto "parecido de familia" [17] que demostró el grado de influencia logrado por los nuevos desarrollos teóricos.

Su ejecución en los países subdesarrollados tuvo efectos devastadores, al agudizar y profundizar los problemas económicos y sociales existentes, generando mayor deterioro en las condiciones de vida de la mayoría de la población.

El impacto de estas políticas repercutieron también sobre los sistemas políticos, ya que la centralidad asignada a la economía, sumada a la crisis de algunos mecanismos propios de los sistemas de representación, afectaron los ámbitos político-institucionales desde los cuales se articulaba la relación entre capital y trabajo. En muchos países el debilitamiento de las instituciones democráticas favoreció el aumento de la corrupción y el fortalecimiento de los poderes de algunos grupos sociales que utilizan estrategias tradicionales para instalar sistemas oligárquicos de dominación (clientelismo, prebendarismo, populismo).[18]

El fin último perseguido con la aplicación de estas políticas, era el de crear condiciones que facilitaran un proceso de acumulación de capital, ya que los teóricos neoliberales consideraban que la causa principal de la crisis en las sociedades desarrolladas, era la de haber redistribuido en exceso durante el período de postguerra, perjudicando al capital.

La senda del crecimiento económico se concretaría retornando a las fuentes originarias de la teoría económica, que le asigna a la lógica del mercado, el valor de "principio rector" de todos los comportamientos humanos. Esta idea, elevada a la categoría de "dogma" sirvió para transformar a los economistas neoliberales en los "nuevos sacerdotes" autorizados para generar propuestas de alcance global. Los ámbitos de Educación, Salud, Viviendas, Previsión Social, etc. se vieron invadidas por el cálculo especulativo propio de las relaciones de intercambio económico y en consecuencia los valores de solidaridad y justicia redistributiva fueron reemplazados por criterios de eficacia y productividad.

La mercantilización de las relaciones sociales aumentó, en la medida que se impuso el razonamiento económico sobre el político. Algunas de las instituciones multilaterales, creadas en la segunda parte del siglo $\mathrm{XX}$, con el fin de evitar las crisis económicas (FMI,BM) modificaron sus funciones originarias y en el caso del Banco, canalizó fondos 
para promover reformas, como las de salud y educación, áreas que no se encontraban definidas en sus objetivos fundacionales. [19]

El sentido de esas políticas era el de contribuir a realizar los cambios que se consideraban necesarios para responder a las exigencias del mundo globalizado. El buen funcionamiento de la economía mundial dependía de que se lograran condiciones favorables para facilitar la movilidad del capital y para ello se hacía imprescindible la vigencia de normas universales orientadas en el mismo sentido. Para lograr esas metas las reformas económicas implicaban también, en muchos casos, reformas políticas y sociales cuyo grado y profundidad dependía del grado de desarrollo alcanzado como "modelos social de bienestar".

Desmantelar una organización institucional para instalar las condiciones requeridas por el nuevo modelo de desarrollo, requería de acciones destinadas a lograr la adhesión, explícita o implícita, de la sociedad.

La crítica al "estado empresario", la contraposición entre "eficiencia privada ineficiencia pública", el burocratismo estatal, etc. eran algunos de los argumentos más utilizados para justificar los cambios, y la necesidad de imponer un estilo de vida, funcional al nuevo modelo social, requería la utilización de todos los sistemas a través de los cuales fuese posible construir el consenso: medios de comunicación, organizaciones profesionales y empresarias, foros académicos, financiación de programas, etc.

La educación, por su grado de incidencia en los comportamientos sociales, se convertía también en un objetivo estratégico, aunque de forma diferente a la que históricamente se le había atribuido, en razón de que los medios de comunicación y los sistemas informáticos introdujeron nuevas formas de acceso a los conocimientos.

Sin embargo como la educación formal sigue cumpliendo una función legitimadora de saberes, se le asigna un lugar importante para el desarrollo de la "sociedad del conocimiento". [20]

La imposición de criterios mercantilistas en las relaciones sociales, operó en el espacio educativo de dos maneras:

1.- Las políticas descentralizadoras, que era uno de los pilares en las reformas del Estado, tenían como función producir un efecto cascada sobre la sociedad, ya que su objetivo era trasladar las responsabilidades de las acciones, desde los niveles centrales a las instancias menores. En términos de los principios y valores de la filosofía liberal, el retiro del Estado de su función redistributiva, coloca en el individuo y su entorno más cercano, la posibilidad de la realización de su proyecto personal. Las políticas educativas, influidas por estas ideas, limitaban la responsabilidad del Estado a la atención de la educación básica, utilizando como argumento el principio de "compensación". Si el Estado reducía su responsabilidad al sostenimiento de la educación básica, el acceso y permanencia en los otros niveles del sistema se transformaba en decisión de los individuos y su familia. En palabras de Guadagni "la escuela debería tender hacia un sistema que priorice el financiamiento de la demanda familiar y/o personal de servicios 
educativos, por sobre la oferta de los establecimientos, tendiendo a restaurar la responsabilidad prioritaria de la familia y la persona. Este sistema permitiría promover la calidad educativa al obligar a los establecimientos públicos a competir para captar alumnos".[21]

Esta reformulación de las responsabilidades que le cabe al Estado y la familia en la provisión de educación., favorece a quienes la consideran (principalmente en los niveles superiores) como un buen negocio y una posibilidad más de inversión para los capitales financieros. Los cambios en las normativas que rigen el funcionamiento del sistema educativo es una condición necesaria para alcanzar esos objetivos, en la medida que faciliten el crecimiento del sector privado. En la Argentina, la Ley Federal de Educación y la Ley de Educación Superior favorecen el crecimiento de estas tendencias.

2.- La flexibilización, que es otra de las ideas-fuerza de la reforma económica y social se expresa en el terreno de las políticas educativas, promoviendo y facilitando una "especialización fragmentaria".

Las modalidades en el nivel medio y superior, formaron parte, históricamente, de los modelos sociales implícitos en los proyectos políticos. La formación del ciudadano, que era una de las tareas prioritarias para la mayoría de los gobiernos democráticos, se le sumaba la de ser, técnico o especialista, artista, agricultor, contable, trabajador industrial, maestra/o, bachiller, etc. ya que esas especializaciones constituían los "recursos humanos" requeridos en un hipotético futuro. En el caso de los gobiernos que compartían los principios de la planificación, estas modalidades expresaban el tránsito hacia otro modelo social y la dirección y secuencia de los cambios era una atribución incuestionable del poder político.

En las últimas décadas y al introducirse lógicas derivadas del cálculo especulativo en los niveles de decisión política, se considera que las modalidades en los niveles medio y superior, son aquellas que deben ofrecer respuestas a una demanda (real, supuesta, deseada o imaginada) múltiple y cambiante, que se deriva de la forma como redistribuye el mercado; como así también de considerar que el modelo de desarrollo exitoso en cada sociedad será aquel que mejor responda a la demanda de una economía globalizada.

La formación instrumental brindada por la educación, debería responder, según este razonamiento, a las actividades requeridas para la construcción del nuevo modelo social, cuya dinámica la impone el funcionamiento del libre mercado. Estas ideas limitan el alcance de las propuestas a una educación para el empleo, la que en un contexto de creciente competencia, favorece la oferta de múltiples y en algunos casos "sofisticadas" ofertas de certificación, que se disputan las expectativas que la sociedad coloca sobre la educación.

Carreras cortas, tecnicaturas, especialidades, capacitación, actualización, son algunas de las alternativas que el sector privado concibe como el nuevo negocio educativo, favorecido por deficiencias o carencias de normativas, que regulen estas 
actividades.

La educación como capital adquirido por el individuo y que fue la base de la teoría del capital humano, hoy se encuentra en crisis, debido a que la posibilidad de acceso a un puesto laboral no depende, tanto del nivel alcanzado dentro del sistema, como del circuito a través del cual se accedió a ese nivel.

El debilitamiento de la capacidad de decisión política de los Estados, ha favorecido el poder del capitalismo financiero transnacionalizado. Muchas de las resoluciones adoptadas por los gobiernos, responden más a los intereses de ese poder, que a las necesidades de su propia sociedad.

La educación se ha transformado en una nueva posibilidad de inversión, como así también un sistema de formación que permite a las empresas incorporar, mediante estrictos mecanismos de selección, a los mejor capacitados para dinamizar sus negocios.

La desocupación vuelve a convertirse en un mecanismo disciplinador, favoreciendo el proceso de selección de los que van a ingresar en el sistema productivo. Una mayoría de quienes transitaron por los diferentes niveles del sistema educativo, o tienen sus credenciales desvalorizadas o forman parte del ejército de excluidos.

La educación ha dejado de ser un "capital" de las personas, para transformarse en un "recurso" que pretende ser administrado por el capital, con el objetivo de que sirva exclusivamente al proceso de acumulación.

La educación "para el capital", constituye uno de los principales componentes de la "sociedad del conocimiento", ya que los saberes a los que se refiere ese concepto se relacionan de forma directa con la producción. Drucker, aclara el sentido de estas afirmaciones cuando expresa que "el recurso económico básico, el "medio de producción", para utilizar los términos de los economistas, ya no es el capital ni los recursos naturales, ni la mano de obra. Es y será el saber (....) el valor se crea mediante la productividad y la innovación, ambas aplicaciones del saber al trabajo". [22]

Considerar a la educación, como un buen negocio o como mecanismo de selección de los "más aptos", es la filosofía que introdujo el neoliberalismo en las sociedades, contradiciendo la función histórica que las sociedades le asignaron.

Mercantilizar la educación o recuperar su función de herramienta liberadora de la "conciencia ingenua", (Freire) constituyen los términos antagónicos de la reflexión dialéctica del presente.

En la resolución de ese antagonismo, se juega el futuro de las mayorías sociales de nuestras sociedades.

\section{5 - CONCLUSIONES}

Este breve paneo sobre la evolución de la relación entre educación y trabajo en la modernidad, nos ha permitido mostrar algunas de sus características .

Lógicamente que sería un grave error afirmar que la forma como se desarrolló este vínculo ha sido uniforme y constante en todos los países, sin embargo, no puede negarse 
que la influencia entre los diferentes procesos sociales, ha sido creciente y por lo tanto no existen acontecimientos que puedan ser considerados como absolutamente originales.

La función política de la educación constituyó una tarea prioritaria en los momentos de conformación de los estados nacionales. Forjar una identidad a partir de compartir una misma interpretación del pasado, incorporar valores, principios y símbolos identitarios, adquirir hábitos para la convivencia social, fueron algunas de las tareas que le fueron reconocidas y exigidas a la educación.

Los sistemas educativos nacionales sirvieron para universalizar esta formación y como manifestamos en el inicio, fábrica y escuela, pertenecen a una misma matriz social, producto no de elucubraciones abstractas, sino de las necesidades de desarrollo de la sociedad.

La educación como mecanismo de formación para incorporarse al mundo del trabajo, atravesó por diferentes momentos, y fue también ámbito de profundos debates.

En el centro de esa polémica es posible identificar distintos modelos sociales, que mantienen entre ellos, diferencias de magnitudes variadas. En los casos más antagónicos estas diferencias se refieren a la manera de concebir al ser humano en su relación con la naturaleza para dominarla, con sus pares, con los instrumentos técnicos creados para satisfacer las necesidades o con la explicación sobre el origen de todo lo existente.

Esa confrontación, que se universalizó en nuestras sociedades desde los orígenes de la modernidad, ocupó un lugar central en el debate y en las práctica políticas durante el siglo XX. Su proyección en el nuevo siglo dependerá de múltiples circunstancias ya que como

Eric Hobsbawm nos enseña "ser capaz de identificar las tendencias generales no equivale a poder predecir qué consecuencias concretas tendrán en la circunstancias del futuro, que, aparte de ser complejas, son en muchos sentidos desconocidas" [23]

El mundo del trabajo ha sufrido, en las últimas décadas, profundas transformaciones que pusieron en crisis muchas de las categorías que se utilizaban en el pasado para identificar y definir su ubicación como uno de los componentes centrales de las relaciones sociales. Los sectores de la sociedad más afectados por estas nuevas condiciones son, en general, los jóvenes. La mayoría de los estudios que analizan las realidades que viven estos grupos sociales en su relación con el mundo laboral, coinciden en que "la transición a la vida adulta bajo un esquema de etapas que se inicia en los estudios escolares y finaliza en la incorporación posterior al mercado laboral, ha dejado de operar como el recorrido vital predominantemente entre los jóvenes. [24]

Frente a esa realidad, la educación que en el pasado representaba una expectativa optimista sobre el futuro, ha perdido esa consideración. Las investigaciones dejan en evidencia, que " en las últimas décadas el sistema educativo habría perdido la capacidad de convertirse en un canal de movilidad ascendente; incluso llega a afirmarse que en el caso de la Argentina la escuela secundaria dejó de jugar su rol como mecanismo de 
homogeneización de oportunidades para quienes puedan terminarla (Filmus y Miranda, 2004, p.9) [25]

Las reformas educativas, que formaron parte, junto a las reformas económicas, sociales y políticas en las últimas décadas del siglo $\mathrm{XX}$, de los programas neoliberales neoconservadores, fueron un intento por subordinar el sistema educativo al sistema económico, limitando sus proyecciones.

Siguiendo las tendencias de estos desarrollos teóricos, la reforma argentina concibió una educación básica, con régimen obligatorio de diez años y luego " el período post-obligatorio lo cursarán normalmente adolescentes de entre 15 y 17 años al término de la Educación General Básica y les brindará apoyo para decidir y avanzar en un proyecto personal sólido, participar en la vida democrática, desempeñarse en el mundo laboral y continuar estudios superiores". [26]

La culminación de la formación de grado se realiza en el "Polimodal" que tiene como función la de "ofrecer a sus alumnos la posibilidad de completar las capacidades generales con el aprendizaje de capacidades específicas que le permitan trabajar en un campo laboral concreto, es decir cursar los Trayectos Técnicos Profesionales" (TTP) [27].

Las modalidades propuestas para ese nivel del sistema educativo se refieren a:

- $\quad$ Producción de Bienes y Servicios

- $\quad$ Economía y Gestión de las Organizaciones.

- Comunicación, Artes y Diseño.

- Ciencias Naturales

- Humanidades y Ciencias Sociales

Los TTP, son concebidos como instancias de formación permanente en función de las demandas del mundo laboral. Si bien se proponen algunas modalidades relacionadas con la Industria (Equipamiento e Instalaciones Industriales) o el sector Agropecuario (Producción agropecuaria), "En el sector servicios la oferta de TTP es más amplia:

Comunicación multimedial.

- Gestión Organizacional.

- Informática Personal y Profesional.

- Salud y Ambiente.

- $\quad$ Tiempo Libre, Recreación y Turismo " [28]

Estas orientaciones para la formación profesional, ponen el énfasis en un modelo de desarrollo basado en el crecimiento de las actividades de "servicios", ya que desde el poder político en la década de los ' 90 , se concebía las posibilidades de inserción del país en el mundo globalizado.

La filosofía implícita en la reforma educativa en la Argentina, estuvo impregnada de la subordinación de la Política a la Economía y en ese sentido no se diferenció del resto de las políticas sociales.

La fragmentación del Sistema en veinticuatro jurisdicciones, introduce un elemento más al desequilibrio del sistema educativo ya que si bien la Ley Federal de Educación 
contempla instancias de articulación (Consejo Federal de Cultura y Educación) en la práctica cada jurisdicción actúa de acuerdo a las condiciones y necesidades políticas de los que grupos de poder local. [29]

En la actualidad existe una reformulación de las Políticas Educacionales desde el Ministerio Nacional, como consecuencia del cambio de orientación política del actual gobierno, sin embargo las tendencias puestas en acción en los '90, continúan vigentes en algunas jurisdicciones, en el sector privado y en algunos centros de producción académica.

El debate sobre la formación que debe ofrecer la educación para concretar con autonomía un modelo social que priorice la inclusión y fomente la solidaridad, deberá ocupar un lugar central en la reconstrucción de la sociedad luego de la "tormenta neoliberal".

El trabajo, que tanta importancia posee en la realización del ser humano, deberá recuperar su sentido integrador, desplazando las tendencias que le asignan una mera función instrumental ligada al cálculo especulativo emergente de la oferta y la demanda. Así como las sociedades deberán asumir una defensa de la naturaleza antes que la voracidad del capitalismo destruya el habitat de todos, también se deberán reorganizar las relaciones sociales para evitar la exclusión y la marginalidad, que son los resultados visibles y evidentes de las políticas neoliberales. Las nuevas tecnologías aplicadas a la producción, no deberán ser utilizadas como argumento para justificar el desplazamiento de los trabajadores. Los avances de la ciencia, que son en última instancia un resultado de la acción colectiva, deben servir para mejorar las condiciones de vida de la humanidad y no para incrementar el lucro desmedido del capital, en base a la super - explotación de los trabajadores.

Educación y trabajo expresan una unidad de sentido, siempre y cuando la educación sea concebida como instrumento para la comprensión de los fenómenos sociales y no como mera herramienta de adaptación al mundo del trabajo y el trabajo aportará a los procesos educativos en la medida que recupere su carácter integrador y su sentido humanizante.

\section{BIBLIOGRAFIA CITADA}

[1] Fernández Enguita, M. La escuela a examen. Edit. EUDEMA Madrid.1993

[2] Gadotti, M. Historia de las ideas pedagógicas. Editorial Siglo XXI. México

[3] Manacorda, Mario A. Historia de la Educación Tomo 2. Siglo XXI Editores. México 1999. Pág. 384 
[4] Manent, P. Historia del pensamiento liberal. Emece Editores. Bs. As. 1990

[5] Oszlak,O. La formación del Estado Argentino. Editorial de Belgrano. Bs.As. 1985

[6] Sayer,D. Capitalismo y Modernidad. Ed. Losada. Bs.As. 1995

[7] Portelli, H. Gramsci y el bloque histórico. Siglo XXI Editores. Mexico 1997.

[8] Manacorda, M. op.cit. Pág. 392

[9] Dussell, I., Caruso M La invención del Aula. Santillana.Bs. As. 1999. Pág.36.

[10] Dussell y Caruso. op.cit Pág 36

[11] Barrancos D. Educación, cultura y trabajadores. Centro Editor de América Latina. Bs. As. 1991.

[12] Pineau, P. en "Estudios de Historia de la Educación durante el primer peronismo". Edit. Los libros del Riel. Bs. As. 1997. Pág. 206 1994.

[13] Gil Villa, F. Teoría Sociológica de la Educación. Amaru Ediciones. Salamanca

Pág. 50 y ss.

[14] Gil Villa,F. Op.cit pág 53

[15] Trilla, J. Ensayos sobre la escuela. Editorial Laertes. Barcelona 1986

[16] Se detacan por su producción e influencia: Gaudencio Frigotto, Acacia Kuenzer; Miguel Arroyo, Paolo Nosella; Pablo Gentili, entre otros.

[17] Nun, J. Democracia. ¿Gobierno del pueblo o gobierno de los políticos? Fondo de Cultura Económica. Bs.As. 2000.

[18] Collor de Melo (Brasil); (Fujimori (Perú); Menem (Argentina); (Pinochet (Chile), son algunos de los ejemplos paradigmáticos surgidos al amparo de estas políticas.

[19] Torres, R.M. La educación según el Banco Mundial. Miño y Davila Editores. Bs.As.1997.

[20] Este concepto proviene del campo de la gestión empresaria (formación del Management) y hace referencia al valor que tiene hoy, en el mundo de los negocios, la información como capital. Peter Druker considera que las actuales sociedades se encuentran en la etapa del post-capitalismo y que el poder es una consecuencia del desarrollo de los conocimientos.

[21] Guadagni, A. En busca de la escuela perdida. Instituto Di Tella - Siglo XXI. Bs. As. 2002. Pág. 196 Pág.14

[22] Drucker, P. La sociedad postcapitalista. Editorial Sudamericana. Bs. As. 1993.

[23] Hobsbawm, E. Sobre la historia. Editorial Crítica. Barcelona 1998. Pág.32

[24] Valdivia Vargas, N. "Dilemas de la inserción laboral de los jóvenes y políticas públicas. En ¿Educar para qué trabajo? Claudia Jacinto (Coordinadora) La crujía Ediciones. Bs. As. 2004. Pág. 280.

[25] Idem pág. 290. 
[26] Zona Educativa. Revista oficial del Ministerio de Cultura y Educación de la Nación. Año 2 Nro. 14 . Junio 1997. Pág. 26

[27] Idem pág. 28

[28] Idem pág. 29

[29] Un trabajo que analiza comparativamente las políticas educativas en las jurisdicciones y pone en evidencia el manejo discrecional en muchas de ellas es: Rivas, A. Gobernar la Educación. Ediciones Granica. Bs. As. 2004 